\title{
CHEMOTHERAPY AND ANTIBIOTIC-RESISTANCE TRANS- FER BETWEEN ENTEROBACTERIA IN THE HUMAN GASTRO-INTESTINAL TRACT
}

\author{
J. D. ANDerson, W. A. Gillespie AND M. H. Richmond \\ Department of Bacteriology, University of Bristol, University Walk, Bristol BS8 1TD
}

TRANSFER of resistance (R) factors occurs readily between certain Gramnegative organisms in the laboratory, and there has been a tendency to assume that it will occur with equal facility in commensal flora, or in lesions. The Gram-negative flora of the gut is particularly relevant in this connection, because it provides a large population of organisms that might be involved in R-factor transfer and may cause exogenous or autogenous infection.

There have been only three previous direct studies on $\mathbf{R}$-factor transfer in the human gastro-intestinal tract and only one involved the use of antibiotics. Smith (1969) found evidence, in a few instances, of transfer of resistance from ingested R-factor-bearing organisms to a chromosomally "labelled" haemolytic resident strain of Escherichia coli, in a single individual. Wiedemann, Knothe and Doll (1970) fed a known $\mathrm{R}$ factor in strains of $E$. coli of known serotype to three healthy persons but failed to demonstrate detectable R-factor transfer in the absence of selection pressure by ingested antibiotics although there was circumstantial evidence for fragmentation of the plasmid. R-factor transfer probably also occurred in an infant with dysentery who was treated with kanamycin (Farrar et al., 1972). The original isolate of Shigella sonnei contained a $\mathrm{fi}^{+} \mathrm{R}$ factor of molecular weight $70 \times 10^{6}$ that conferred resistance to tetracycline, streptomycin and ampicillin. The Shigella isolated after antibiotic administration contained the original $\mathrm{R}$ factor and also a $\mathrm{fi}^{-}$plasmid of molecular weight $43 \times 10^{6}$ which carried a kanamycin-resistance marker.

Although direct experimental evidence for R-factor transfer in the human gut is scarce, there are strong epidemiological grounds for believing that R-factor transfer to enteric pathogens and non-pathogens may occur (see, for example, the early Japanese work reviewed by Watanabe, 1963; and also Davies, Farrant and Tomlinson, 1968; Gardner and Smith, 1969; Anderson, 1968; and Bohuš, 1971). Furthermore, there is experimental evidence for resistance transfer in the gut of other animals. These investigations were usually made in newborn or germ-free animals or animals receiving antibiotics (see, for example, Kasuya, 1964; Guinée, 1965; Walton, 1966; Salzman and Klemm, 1968; Jarolmen and Kemp, 1969; Smith, 1970).

The above evidence strongly suggests that resistant bacteria may arise in vivo from the acquisition of transferred $\mathrm{R}$ factors, but this interpretation relies heavily on the identification of an $\mathrm{R}$ factor with a given range of resistance determinants in donor and recipient organisms. Since most $\mathbf{R}$ factors contain enough DNA to specify at least 50 gene products (Clowes, 1972), a closer examination of the nature of an R factor is needed if it is to be "identified" with certainty. A study of the number and type of resistance determinants-often only three or four of the total number of gene products specified-is inadequate; and much of the earlier work has been questioned on these grounds (Walton, 1971; Jukes, 1971).

Received 30 Jan. 1973; accepted 14 Feb. 1973.

J. MED. MICROBIOL.-WOL. 6: 1973) 
All relevant bacterial isolates from one of the individuals participating in the present series of experiments were therefore subjected to detailed study described in the succeeding paper (Anderson et al., 1973b) to prove beyond reasonable doubt that $R$-factor transfer can occur in the human gut, and to try to define the conditions under which this process is prevalent. These further studies have relied heavily on DNA/DNA hybridisation to compare a selection of the plasmids in bacteria isolated during various stages of the study. Because this type of interaction depends for its success on the size and detailed base sequence of lengths of DNA in a given preparation (Falkow, Hääpala and Silver, 1969), it provides an additional and more rigorous criterion of " identity " than does a catalogue of plasmid resistance-determinants.

The first step in all the experiments was to isolate strains of $E$. coli from the faeces of each experimental subject. These strains were then marked genetically in the laboratory and fed back to the same subject to act as a potential and easily identifiable plasmid recipient, and also to supplement the endogenous population of $E$. coli. R-factor transfer was then investigated by feeding a different strain of $E$. coli, also marked genetically for identification, that carried an $\mathrm{R}$ factor of known properties. Transfer may be detected by identifying the known plasmids either in the ingested potential recipient organism or in endogenous coliforms other than the marked donor. The process was studied both in subjects before treatment with antibiotics and in those given various courses of suitable agents after feeding the potential donors.

No R-factor transfer could be detected in any experiment in the absence of antibiotic therapy, even though the $R$ factors concerned could be transferred in laboratory studies from the potential donors to many different enteric organisms as recipients, including the genetically marked potential recipients used in these experiments. However, treatment of the subjects with a course of a relevant antibiotic resulted in the emergence of a number of types of resistant organism, some the potential recipients and some not, to which transfer had occurred.

A preliminary account of part of this work has already been published (Anderson, Gillespie and Richmond, 1973a).

\section{METHODS}

\section{Media}

MacConkey bile-lactose agar was prepared with, and without, antibiotics. Incorporation plates were prepared that contained the following antibiotics: ampicillin, $25 \mu \mathrm{g}$ per ml; chloramphenicol, $25 \mu \mathrm{g}$ per ml; nalidixic acid, $50 \mu \mathrm{g}$ per ml; rifampicin, $50 \mu \mathrm{g}$ per ml; streptomycin, $10 \mu \mathrm{g}$ per $\mathrm{ml}$; tetracycline, $25 \mu \mathrm{g}$ per $\mathrm{ml}$; nalidixic acid, $50 \mu \mathrm{g}$ per $\mathrm{ml}$, with ampicillin, $25 \mu \mathrm{g}$ per $\mathrm{ml}$; nalidixic acid, $50 \mu \mathrm{g}$ per ml, with tetracycline, $25 \mu \mathrm{g}$ per ml; rifampicin, $50 \mu \mathrm{g}$ per ml, with ampicillin, $25 \mu \mathrm{g}$ per ml; and rifampicin, $50 \mu \mathrm{g}$ per ml, with tetracycline, $25 \mu \mathrm{g}$ per ml. MacConkey medium has the disadvantage, however, that it cannot be used to determine populations of sulphonamide-resistant organisms and occasionally gives low estimates of streptomycin-resistant organisms.

Antibiotic-sensitivity tests by the filter-paper-disk technique were performed on plates of Oxoid (Oxoid Ltd, London S.E.1) DST Agar supplemented with saponin-lysed oxalated horse blood ( 5 per cent.).

Nutrient broth was used for in-vitro resistance-transfer studies. 


\section{Investigation of faecal flora}

Specimens of faeces were usually studied within $3 \mathrm{hr}$ of voiding. Portions of about $0.5 \mathrm{~g}$ were emulsified with saline ( 9 parts $\mathrm{v} / \mathrm{w}$ ) by agitation with glass beads. Viable counts of antibiotic-sensitive and -resistant Gram-negative bacilli were determined by the Miles, Misra and Irwin (1938) technique on MacConkey agar with, and without, appropriate antibiotics. Lactose-fermenting organisms ("coliforms") and non-lactose fermenting organisms (NLFs) were estimated separately, and a selection of each was identified biochemically (Cowan and Steel, 1965). These methods could detect as few as $10^{3}$ to $10^{4}$ organisms per $\mathrm{g}$ of faeces. The coefficient of variation of coliform counts on replicate samples of faeces was about 16 per cent.

A selection of between two and ten antibiotic-resistant colonies was picked from each antibiotic incorporation-plate and the sensitivity pattern studied further on lysed-blood agar plates by means of filter-paper disks containing ampicillin, $50 \mu \mathrm{g}$; chloramphenicol, $50 \mu \mathrm{g}$; colistin, $200 \mu \mathrm{g}$; kanamycin, $30 \mu \mathrm{g}$; nalidixic acid, $30 \mu \mathrm{g}$; nitrofurantoin, $200 \mu \mathrm{g}$; rifampicin, $30 \mu \mathrm{g}$; sulphafurazole, $500 \mu \mathrm{g}$; streptomycin, $25 \mu \mathrm{g}$; and tetracycline, $50 \mu \mathrm{g}$.

Organisms required for further study were either freeze-dried or stored on Dorset-egg or nutrient-agar slopes.

\section{Preparation of antibiotic-resistant organisms for feeding experiments}

Two F-like $f i^{+}$repressed R-factors in strains of $E$. coli donated by Dr Naomi Datta (Royal Postgraduate Medical School, London) were used in this work, because previous studies in this department have given a good knowledge of their molecular characteristics. The plasmid R-222-1 conferred resistance to chloramphenicol, streptomycin, sulphonamides and tetracycline and was derived from a factor originally isolated by Watanabe and Fukasawa (1961). The plasmid R-1 conferred resistance to ampicillin, chloramphenicol, kanamycin, streptomycin and sulphonamides (Meynell, Meynell and Datta, 1968).

Chromosomally labelled mutants of $E$. coli were prepared by inoculating 9-cm-diameter blood-agar plates containing either nalidixic acid $(50 \mu \mathrm{g}$ per $\mathrm{ml})$ or rifampicin $(50 \mu \mathrm{g}$ per $\mathrm{ml})$ with about $10^{10}$ organisms of isolates from the faecal flora of each experimental subject. Isolated mutant colonies which appeared after incubation were purified by repeated subculture on the appropriate selective medium. An $\mathrm{R}$ factor was introduced into some of these chromosomally labelled mutants by overnight incubation at $37^{\circ} \mathrm{C}$ of an inoculum of about $2 \times 10^{6}$ organisms of the donor and $10^{7}$ organisms of the recipient in nutrient broth $(10 \mathrm{ml})$. Organisms resulting from $\mathbf{R}$-factor transfer were isolated and purified on media containing two appropriate antibiotics. In these experiments, transfer of plasmids R-1 and R-222-1 to the genetically marked potential recipient strains of $E$. coli occurred at a maximum frequency of about $2 \times 10^{-3}$ per donor organism per $\mathrm{hr}$ in nutrient broth at $37^{\circ} \mathrm{C}$.

All subjects were given mutants of their "own" strains of $E$. coli, so no adverse effects were anticipated and none occurred. Nevertheless, the presence of enteropathogenic strains of $E$. coli, which might cause mild gastrointestinal symptoms in adults, was largely excluded by a slide-agglutination test with Burroughs Wellcome (Beckenham, Kent) "Poly 2", "Poly 3", and 0-142 antisera. These agglutinate known enteropathogenic strains of $E$. coli in this country. As a further precaution against inducing gastroenteritis that might invalidate the experiments, one of the authors ingested 1 to $5 \times 10^{11}$ cells of each organism without ill-effect.

\section{Bacterial feeding experiments}

All subjects were healthy individuals who had not taken antibiotics for one or more years previously. Subject A was a schoolboy; subjects B, C, D and E, were bacteriologists.

Overnight broth cultures $(20 \mathrm{ml})$ of the chosen organisms were checked for purity, antibiotic-resistance pattern, and viable count. The organisms were then concentrated by centrifugation at $1500 \mathrm{~g}$ for $20 \mathrm{~min}$. and the cell slurry containing $10^{10}$ to $10^{11}$ viable organisms transferred to a gelatin capsule for ingestion with a drink of milk or tomato juice. If two types of organism had to be given in any experiment, the potential recipient was given in the midmorning and the potential donor in the mid-afternoon. 
To determine the effect of antibiotics upon the gut flora, subject $\mathrm{A}$ (weight $38 \mathrm{~kg}$ ) was given $125 \mathrm{mg}$ of ampicillin four times daily for five days, starting on the morning after ingestion of the bacteria. Subjects $\mathrm{C}$ and $\mathrm{E}$ were given $250 \mathrm{mg}$ doses of tetracyline and ampicillin, respectively, at the same time intervals. Fourteen weeks later, subjects $\mathrm{A}, \mathrm{C}$, and $\mathrm{E}$ were each given another 5-day course of the antibiotic that had been given originally.

\section{RESULTS \\ Faecal flora of healthy volunteers}

The findings summarised in table I show that there were large differences in the mean populations of lactose-fermenting "coliforms", NLFs and antibiotic

TABLE I

Characteristics of the aerobic Gram-negative faecal flora of five normal persons (15 to 20 samples collected from each over a period of about 10 weeks)

\begin{tabular}{|c|c|c|c|c|c|}
\hline \multirow{2}{*}{ Character } & \multicolumn{5}{|c|}{ Observations on subject } \\
\hline & A & $\mathbf{B}$ & C & $\mathbf{D}$ & $\mathbf{E}$ \\
\hline Age & 11 & 23 & 40 & 42 & 60 \\
\hline & $\mathbf{M}$ & $\mathbf{F}$ & M & M & $\mathbf{M}$ \\
\hline $\begin{array}{l}\text { Mean"coliform" count per } g \text { of faeces (and } \\
\text { standard error of mean) }\end{array}$ & $\begin{array}{r}3.60 \times 10^{7} \\
\left(1.97 \times 10^{7}\right)\end{array}$ & $\begin{array}{l}2.47 \times 10^{7} \\
\left(1.29 \times 10^{7}\right)\end{array}$ & $\begin{array}{r}6.32 \times 10^{7} \\
\left(1.47 \times 10^{7}\right)\end{array}$ & $\begin{array}{l}3.39 \times 10^{3} \\
\left(1.48 \times 10^{5}\right)\end{array}$ & $\begin{array}{r}4.85 \times 10^{\circ} \\
\left(1.81 \times 10^{6}\right)\end{array}$ \\
\hline $\begin{array}{l}\text { Mean count of non-lactose-fermenting } \\
\text { organisms per } g \text { of faeces (and standard } \\
\text { error of mean) }\end{array}$ & 0 & $\begin{array}{r}2.22 \times 10^{7} \\
\left(7.67 \times 10^{6}\right)\end{array}$ & $\begin{array}{r}3.00 \times 10^{2} \\
\left(2.06 \times 10^{2}\right)\end{array}$ & $\begin{array}{l}4.19 \times 10^{4} \\
\left(3.92 \times 10^{3}\right)\end{array}$ & 0 \\
\hline $\begin{array}{l}\text { Percentage of samples of faeces in which } \\
\text { antibiotic-resistant organisms were de- } \\
\text { tected }\end{array}$ & 33 & 38 & 37 & 38 & 100 \\
\hline Antibiotic-resistant organisms as percentage & 0.43 & 0.01 & 0.02 & $8 \cdot 4$ & 13.8 \\
\hline $\begin{array}{l}\text { Mean number of antibiotic-resistance de- } \\
\text { terminants detected in each type of resist- } \\
\text { ant organism isolated from each specimen } \\
\text { of faeces }\end{array}$ & 1.20 & 1.64 & 2.00 & $2 \cdot 40$ & 2.65 \\
\hline
\end{tabular}

resistant organisms, in the faeces of five healthy subjects. The "coliforms" were predominantly ( $>97$ per cent.) strains of $E$. coli and the NLFs predominantly ( $>95$ per cent.) Proteus spp. The relatively high standard error in the value of each mean bacterial population provides a numerical expression of the large day-to-day variation in the components of the faecal flora.

An incidental and unexpected finding was that the mean number of antibiotic-resistance determinants in each type of resistant organism rose significantly with the age of the subject (the data fit a straight line with a regression coefficient of $0.973 ; \mathrm{P}=<0.01$ ).

To find out how long ingested organisms survive in the gut, four of the subjects were fed with chromosomally marked rifampicin- or nalidixic-acidresistant mutants of $E$. coli prepared from sensitive parent strains isolated from their own faeces. Preliminary experiments suggested that high viable counts of $E$. coli in the faeces could be obtained after the ingestion of a single dose of between $10^{10}$ and $10^{11}$ organisms. The results summarised in table II show that, 
although the gut was colonised to about the same degree in all subjects, there were large variations in the survival of ingested organisms in each case. Although the endogenous flora was at first overwhelmed by the large number of ingested organisms, these organisms themselves were displaced in turn by resident or dietary flora.

\section{$R$-factor transfer in the absence of antibiotics}

To determine the extent of R-factor transfer in the gut, four volunteers ingested the same four chromosomally marked $E$. coli strains used in the above experiment, followed after a few hours by organisms containing a different chromosomal antibiotic-resistance marker and a known multi-resistant $\mathbf{R}$ factor. Despite the artificially large populations of potential donor and recipient

TABLE II

Colonisation of the gut of four persons after the ingestion of "chromosomally marked" antibiotic-resistant strains of Escherichia coli

\begin{tabular}{|c|c|c|c|c|}
\hline \multirow{2}{*}{ Character } & \multicolumn{4}{|c|}{ Observations on subject } \\
\hline & $\mathbf{A}$ & B & C & $\overrightarrow{\mathbf{E}}$ \\
\hline $\begin{array}{l}\text { Resistance marker* } \\
\text { Number of viable organisms ingested } \times 10^{-10} \\
\text { Maximum observed count of "chromosomally marked" } \\
\text { organism in faeces (as a percentage of the total faecal } \\
\text { aerobic Gram-negative flora) }\end{array}$ & $\begin{array}{c}\mathbf{R f} \\
6.0 \\
100\end{array}$ & $\begin{array}{c}\text { NA } \\
1.4 \\
103\end{array}$ & $\begin{array}{l}\mathrm{Rf}_{4.0} \\
88\end{array}$ & $\begin{array}{c}\text { NA } \\
9.0 \\
96\end{array}$ \\
\hline $\begin{array}{l}\text { Persistence (in days) of detectablenumbers of "chromosom- } \\
\text { ally marked" organisms in the faeces }\end{array}$ & 24 & 8 & 12 & 9 \\
\hline
\end{tabular}

* $R f=$ resistance to rifampicin; $N A=$ resistance to nalidixic acid.

organisms, none was detected with marker patterns suggesting plasmid transfer to endogenous or ingested recipients (limits of detection about $10^{3}$ organisms per $g$ of faeces in these experiments). The results summarised in table III show that, on 16 occasions on which the ingested laboratory donor and recipient organisms were present together in specimens of faeces, their mean numbers were such that one would have expected transfer to have occurred had the organisms been in broth. Once again, as in the previous experiment, there were large variations in the persistence of the various organisms.

\section{$R$-factor transfer in the presence of antibiotics}

To test the hypothesis that antibiotic administration may increase the resistant populations resulting from $\mathbf{R}$-factor transfer in the gut, the above experiment was repeated on three of the volunteers, but on the day after ingestion of organisms a five-day course of antibiotic treatment was started. The antibiotic dose and duration of treatment correspond to the minimum used in clinical practice. Results for subject $\mathrm{E}$ will be considered in detail, and those of subject $\mathrm{A}$ and $\mathrm{C}$ in outline. 


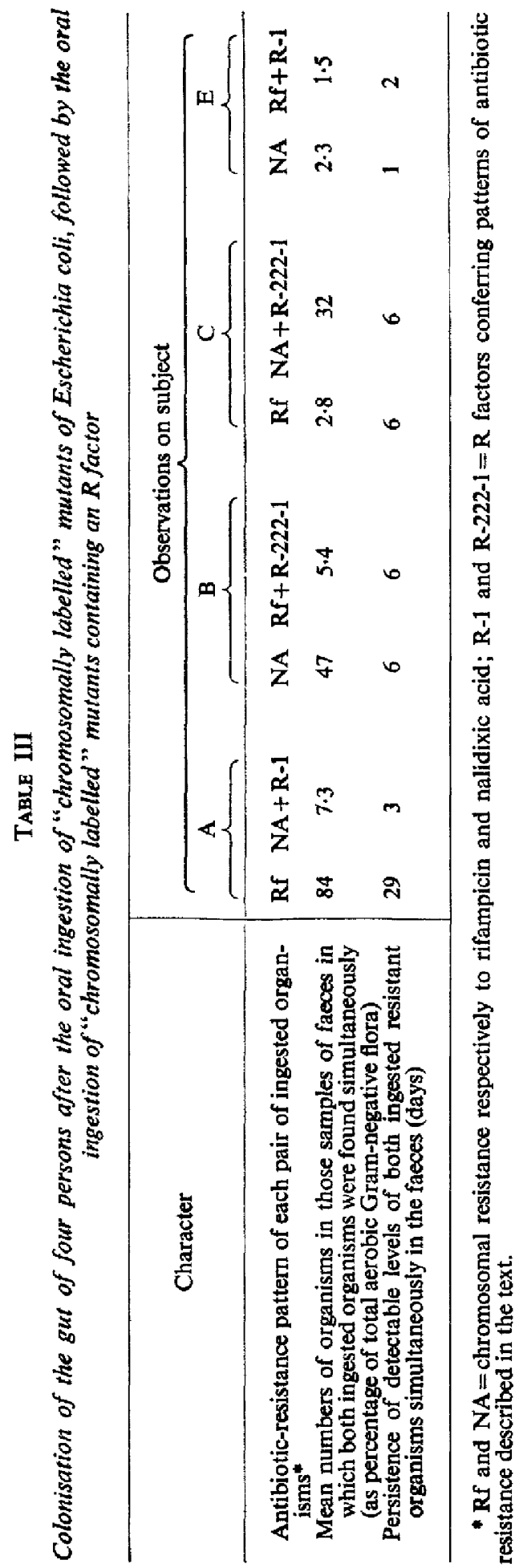


Table IV summarises the feeding regimen and bacteriological findings for subject E. Once again, there were large day-to-day variations in total bacterial numbers, which were perhaps exaggerated by the intake of bacteria and antibiotics. Surprisingly, there was no evidence of transfer of $\mathbf{R}$ factors from the donor organism to the nalidixic-acid-resistant potential recipient organism that had been ingested. However, a large number of "coliforms" was isolated with resistance determinants consistent with the transfer of the plasmid R-1 to the subjects' endogenous strains of $E$. coli. These new resistant organisms formed the predominant flora of the faeces over the period from the 7th to 37th day from the start of the experiment and survived for 29 days longer than the donor organism from which, presumably, they had been derived. All the resistance determinants characteristic of plasmid R-1 were transferred in vitro from all these isolates into a laboratory strain of $E$. coli (transfer frequency approximately $2 \times 10^{-3}$ per donor organism per $\mathrm{hr}$ ). On only two occasions a few colonies of $E$. coli were also isolated from the faeces with an antibiotic resistance pattern consistent with transfer of plasmid R-1 to a tetracycline-resistant strain of E. coli. Resistance determinants for plasmid R-1 and for tetracycline could be transferred only together, and at low frequency (less than $5 \times 10^{-10}$ per donor organism during overnight incubation), to laboratory strains of $E$. coli.

Although this experiment was continued for a total of 16 weeks and the course of ampicillin treatment was repeated at the 14th week no organisms were isolated after 37 days with a resistance pattern indicating possible origin from the original plasmid R-1.

An expected incidental finding was the change in the gut flora after ampicillin treatment. Organisms with a combination of resistance determinants differing from those of the R-1 plasmid were assumed to be of dietary or endogenous origin, although the possibility of fragmentation and recombination of the plasmid R-1 cannot be excluded (see Discussion). During the 18 days after the start of the first course of ampicillin, the endogenous resistant flora consisted mainly of organisms with between one and three resistance determinants, which included ampicillin. This contrasted with the period of some months before and after treatment, when tetracycline, streptomycin and sulphonamide resistance had predominated. The second course of treatment with ampicillin also caused ampicillin-resistant organisms to predominate in the faeces within a few days; and, as expected, these were in turn displaced by organisms with the resistance pattern usually found in the faeces of this subject.

In a similar experiment, subject $A$ was fed with a rifampicin-resistant mutant of his "own" E. coli, followed by a nalidixic-acid-resistant mutant of this organism containing the $\mathrm{R}$ factor $\mathrm{R}-1$, and a five-day course of treatment with ampicillin. Organisms appeared in the faeces with a marker pattern consistent with transfer of plasmid R-1 to the ingested rifampicin-resistant mutants. These organisms formed 90 per cent. of the aerobic Gram-negative flora on one occasion and persisted for 13 days. Although ampicillin treatment at first reduced the rifampicin-resistant $E$. coli in the faeces to undetectable numbers, this organism reappeared when chemotherapy was stopped and persisted at high levels ( $>40$ per cent.) for 30 days, and at detectable levels for 69 days. 


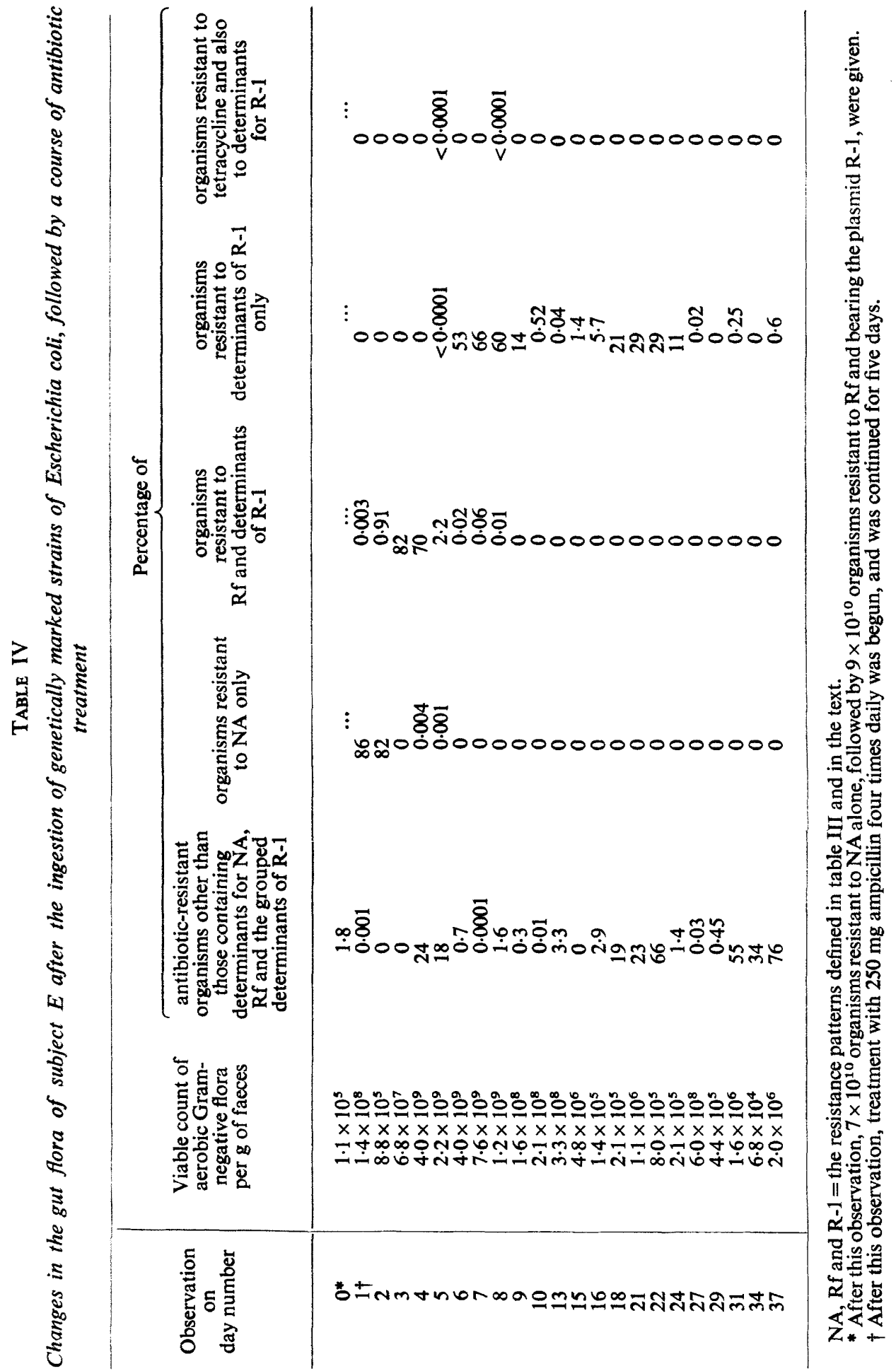


Subject $\mathrm{C}$ was fed with a rifampicin-resistant mutant of $E$. coli followed by a nalidixic-acid-resistant mutant of another strain containing the $R$ factor R-222-1 followed by a five-day course of treatment with tetracycline. As with subject $\mathrm{E}$, there was no detectable evidence of transfer to the ingested potential recipient strain. The resistance pattern of organisms isolated from faeces suggested that there may have been transfer of plasmid R-222-1 to an endogenous sensitive population of $E$. coli and this resistant population persisted for 58 days in numbers that varied between $0 \cdot 2$ per cent. and 36 per cent. of the intestinal aerobic Gram-negative flora. After 58 days, both ingested strains still formed about 0.5 per cent. each of the aerobic faecal flora. As expected, the second course of chemotherapy increased the populations of the appropriate resistant organisms in subjects $\mathbf{A}$ and $\mathbf{C}$.

\section{TABLE V}

Effect of a five-day course of ampicillin or tetracycline on the persistence of ingested $R$ factors in the faeces of three persons*

\begin{tabular}{|c|c|c|c|}
\hline \multirow{2}{*}{ Character } & \multicolumn{3}{|c|}{ Observations on subject } \\
\hline & A & $\mathrm{C}$ & $\mathbf{E}$ \\
\hline $\begin{array}{l}\text { Fed with Escherichia coli containing } \mathrm{R} \text { factort } \\
\text { Persistence (in days) of ingested } \mathrm{R} \text { factor in detectable numbers } \\
\text { in the absence of antibiotic treatment }\end{array}$ & $\begin{array}{r}\text { R-1 } \\
3\end{array}$ & $\begin{array}{c}\mathrm{R}-222-1 \\
6\end{array}$ & $\begin{array}{c}\mathrm{R}-1 \\
2\end{array}$ \\
\hline $\begin{array}{l}\text { Persistence (in days) of ingested } R \text { factorin detectable numbers } \\
\text { after treatment with a five-day course of ampicillin or tetra- } \\
\text { cycline }\end{array}$ & $>69$ & $>58$ & 37 \\
\hline
\end{tabular}

* For details of antibiotic treatment see text.

$\dagger$ For antibiotic-resistance patterns of the $R$ factors see text.

In each of the subjects $\mathrm{A}, \mathrm{C}$, and $\mathrm{E}$, antibiotic therapy also greatly increased the length of time during which ingested $\mathrm{R}$ factors could be detected in the faeces (table V).

\section{Evidence against loss or fragmentation of $R$ factors in genetically marked ingested $E$. coli}

Any fragmentation or loss of $\mathrm{R}$ factors from chromosomally marked ingested organisms could be inferred from changes in the resistance pattern of organisms isolated from faeces on antibiotic-incorporation plates containing an antibiotic selecting for the chromosomal resistance determinant only. All of a selection of 276 such colonies contained all the resistance determinants of the ingested $R$ factor. Loss or fragmentation of those genes of the $\mathrm{R}$ factors in the ingested organisms that determine antibiotic resistance is therefore unlikely.

\section{Discussion}

Bacteroides are more than 10,000 times as numerous in faeces as are the enterobacteria (Drasar et al., 1969), but these organisms could not be studied because of the technical difficulties of carrying out parallel experiments under anaerobic 
conditions. Although the possibility exists that anaerobes may be involved in $\mathbf{R}$-factor transfer, limited laboratory studies in this Department failed to show any R-factor transfer from one strain of Bacteroides fragilis to another, or to, or from, strains of $E$. coli (Anderson and Sykes, 1973).

No explanation can be offered for the significant positive correlation between the age of an individual and the mean number of resistance determinants in his intestinal flora. The large day-to-day variations in the components of the faecal flora, and the very different patterns observed in the various subjects, indicate the need for caution in drawing any general conclusions from studies on such a small number of selected individuals.

Variations observed in the survival of ingested organisms in the intestinal tract of the experimental subjects were in general similar to those reported by other authors, e.g., Sears et al. (1950); Wiedemann et al. (1969), and Cooke et al. (1972).

Because the available literature suggested that $\mathrm{R}$-factor transfer occurs at or about undetectable levels in the absence of antibiotics, large doses $\left(10^{10}\right.$ to $10^{11}$ ) of R-factor-bearing $E$. coli were given to each individual to increase the possibility of detecting resistant organisms arising by conjugation in the gut. The number of organisms ingested in everyday life are not known, but it is possible to colonise the gut with detectable numbers of some organisms with a single dose of only $10^{4}$ bacteria (Shooter, 1971). R-factor transfer must therefore be a rare event under natural conditions in the absence of chemotherapy, because no transfer was detected when the faeces of these subjects contained up to 1000 or more times the mean population of resistant organisms.

The use of the individual's own $E$. coli as parents for chromosomal and plasmid-labelled derivatives for feeding experiments was designed to minimise the possibility of deleterious effects, and in fact there were none. It was also hoped, as suggested by Smith's (1969) findings, that such laboratory derivatives would resemble the resident flora of the bowel and survive longer than other strains.

When therapeutic doses of ampicillin or tetracycline were given to three healthy volunteers, transient populations of resistant organisms appeared in the faeces that were as large as those obtained after ingesting between $10^{10}$ and $10^{11}$ laboratory organisms. The fact that such changes may follow chemotherapy counters the possible criticism that unduly large numbers of resistant organisms were used in these experiments. R-factor transfer did not occur in the gastrointestinal tract of four healthy persons, in the absence of chemotherapy, at levels that were detectable in these experiments. Wiedemann (1972) has suggested that anaerobic conditions do not explain the low frequency of R-factor transfer in the gut in comparison with that in laboratory media; he has, however, obtained evidence that some bile salts, and metabolic products of Streptococcus faecalis, inhibit R-factor transfer in vitro.

By contrast, the use of therapeutic doses of antibiotics in similar experiments led to the appearance of large populations of resistant organisms with antibiotic marker-patterns consistent with $\mathbf{R}$-factor transfer to the endogenous flora or to genetically marked ingested organisms. This change presumably resulted from 
selection pressure by the antibiotics in favour of the otherwise undetectably small numbers of transcipients normally present in the gut. However, for reasons outlined in the Introduction, studies of resistance marker-patterns alone do not provide satisfactory proof of R-factor transfer. Organisms from subject E were therefore chosen for detailed investigations, including molecular studies on crucial samples, to prove conclusively that R-factor transfer had occurred in this subject, and, by implication, in subjects $\mathrm{A}$ and $\mathrm{C}$; these investigations are described in full in the succeeding paper.

No evidence of fragmentation of R-factors was obtained in the 276 faecal isolates of chromosomally labelled ingested organisms that were examined. The possibility cannot be excluded that it would occur in larger populations over longer periods of time. Furthermore, the experiment would not detect fragmentation occurring during or after transfer of an entire $\mathbf{R}$ factor from a genetically labelled organism, nor the loss of any part of the $\mathbf{R}$ factor not concerned with determining antibiotic resistance.

The greatly increased persistence of ingested $\mathbf{R}$ factors after a short course of chemotherapy is obviously of clinical interest. During antibiotic treatment the numbers of sensitive organisms will be reduced to a minimum, and resistant strains will be selected. At the end of treatment, the proportion of resistant organisms falls slowly while the sensitive bacterial population slowly increases in numbers, presumably either by recolonisation of the gut from outside or by the growth of a few sensitive survivors. Some time after the removal of selection pressure from chemotherapy, there will be a point at which the gut contains a mixture of approximately equal numbers of $\mathbf{R}$-factor-carrying resistant strains and R-factor-less potential recipients. It is in this period that plasmids have the highest probability of transferring to other enterobacteria, and particular care should be taken when it is necessary to give a second course of antibiotic therapy within some months of the original treatment.

\section{SUMMARY}

The transfer of $\mathbf{R}$ factors in the human gastro-intestinal tract and the conditions under which it occurs was studied in healthy persons, who ingested derivatives of Escherichia coli containing chromosomal and R-factormediated resistance determinants that had been prepared from strains isolated from their own faeces. The experiments were designed to obtain presumptive evidence of survival and transfer of $\mathbf{R}$ factors by studying resistance-marker patterns of organisms isolated from the faeces. To prove conclusively that R-factor transfer had occurred and that the observed marker patterns were not fortuitous, studies of resistance-marker patterns in one of these subjects were supplemented by further detailed investigations including serological and molecular studies, which will be described in the succeeding paper.

An incidental finding was a significant positive correlation between the mean number of antibiotic-resistance determinants in resistant organisms and the age of an individual, although these studies were limited to a small and highly selected group of subjects.

No evidence of $\mathbf{R}$-factor transfer was obtained in the absence of chemotherapy 
in four subjects, even though the plasmids concerned could be freely transferred in vitro from the potential donors to a wide range of faecal organisms, including the genetically marked ingested potential recipients. However, treatment of three subjects with a five-day course of a relevant antibiotic after ingestion of $\mathrm{R}$ factor bearing organisms led to the appearance in the faeces of large numbers of resistant coliform bacilli with antibiotic-resistance patterns consistent with transfer of the $\mathrm{R}$ factor either to an ingested potential recipient organism (one subject) or to endogenous strains of $E$. coli (two subjects).

Chemotherapy greatly prolonged the persistence of ingested $\mathrm{R}$ factors in the faecal flora long after the antibiotics were withdrawn and caused the number of $\mathrm{R}$-factor bearing organisms in the faeces to increase. No evidence was obtained in limited studies of fragmentation or loss of $\mathrm{R}$ factors from ingested $E$. coli.

We are most grateful to Mrs $\mathrm{H}$. Clements for her excellent technical assistance and to Dr L. C. Ingram for preparing computer programmes and for advice on statistics. This work was supported by a Programme Grant for molecular and epidemiological studies on R factors and other plasmids from the Medical Research Council.

\section{REFERENCES}

AndzRson, E. S. 1968. The ecology of transferable drug resistance in the enterobacteria. Ann. Rev. Microbiol., 22, 131.

Anderson, J. D., Gillespie, W. A., And Richmond, M. H. 1973a. The effect of antibiotics upon R-factor transfer between strains of Escherichia coli in the human gastro-intestinal tract. J. Med. Microbiol., 6, ix.

Anderson, J. D., Ingram, L. C., Richmond, M. H., AND Wiedemann, B. 1973b. Studies on the nature of plasmids arising from conjugation in the human gastro-intestinal tract. J. Med. Microbiol., 6, 475.

Anderson, J. D., AND SyKes, R. B. 1973. Characterisation of a $\beta$-lactamase obtained from a strain of Bacteroides fragilis resistant to $\beta$-lactam antibiotics. J. Med. Microbiol., 6, 201.

BoHUš, J. 1971. Acceptance of R factor by a Shigella sonnei strain from commensal Escherichia coli strains during dysentery. J. Hyg. Epidem. Microbiol. Immun., 15, 225.

Clowes, R. C. 1972. Molecular structure of bacterial plasmids. Bact. Rev., 36, 361.

CoOke, E. Mary, Hettlaratchy, Ira G., AND Buck, A. C. 1972. Fate of ingested Escherichia coli in normal persons. J. Med. Microbiol., 5, 361.

Cowan, S. T., AND STEEL, K. J. 1965. Manual for the identification of medical bacteria, London.

Davies, Joan R., Farrant, W. N., and Tomlinson, A. J. H. 1968. Further studies on the antibiotic resistance of Shigella sonnei. II. The acquisition of transferable antibiotic resistance in vivo. J. Hyg., Camb., 66, 479.

Drasar, B. S., Shiner, Margot, ANd McLeod, G. M. 1969. Studies on the intestinal flora. I. The bacterial flora of the gastrointestinal tract in healthy and achlorhydric persons. Gastroenterology, 56, 71.

FalKow, S., HäÄPAla, D. K., AND Silver, R. P. 1969. Relationships between extrachromosomal elements. In Bacterial episomes and plasmids, edited by G. E. W. Wolstenholme and Maeve O'Connor, London, p. 136.

Farrar, W. E., Jr, Eidson, Margene, Guerry, Patricia, Falkow, S., Drusin, L. M., and ROBERTS, R. B. 1972. Interbacterial transfer of $R$ factor in the human intestine: in vivo acquisition of R-factor-mediated kanamycin resistance by a multiresistant strain of Shigella sonnei. J. Infect. Dis., 126, 27.

Gardner, P., AND Smith, D. H. 1969. Studies on the epidemiology of resistance (R) factors. I. Analysis of Klebsiella isolates in a general hospital. II. A prospective study of $\mathrm{R}$ factor transfer in the host. Ann. Intern. Med., 71, 1. 
GuINÉE, P. A. M. 1965. Transfer of multiple drug resistance from Escherichia coli to Salmonella typhimurium in the mouse intestine. Antonie van Leeuwenhoek, 31, 314.

JAROLMEN, H., AND KEMP, G. (1969). R factor transfer in vivo. J. Bact., 99, 487.

JUKES, T. H. 1971. The present status and background of antibiotics in the feeding of domestic animals. Ann. N.Y. Acad. Sci., 182, 362.

KasUYA, M. 1964. Transfer of drug resistance between enteric bacteria induced in the mouse intestine. J. Bact., 88, 322.

Meynell, Elinor, Meynell, G. G., and Datta, Naomi 1968. Phylogenetic relationships of drug-resistance factors and other transmissible bacterial plasmids. Bact. Rev., 32, 55.

MILES, A. A., MisRA, S. S., AND IRwIN, J. O. 1938. The estimation of the bactericidal power of the blood. J. Hyg., Camb., 38, 732.

Salzman, C. T., AND KLEMM, Lydia 1968. Transfer of antibiotic resistance (R factor) in the mouse intestine. Proc. Soc. Exp. Biol. Med., 128, 392.

Sears, H. J., Brownlee, I., AND UChiyama, J. K. 1950. Persistence of individual strains of Escherichia coli in the intestinal tract of man. J. Bact., 59, 293.

SHOOTER, R. A. 1971. Bowel colonization of hospital patients by Pseudomonas aeruginosa and Escherichia coli. Proc. R. Soc. Med., 64, 989.

SMITH, H. W. 1969. Transfer of antibiotic resistance from animal and human strains of Escherichia coli to resident $E$. coli in the alimentary tract of man. Lancet, 1, 1174.

SMITH, H. W. 1970. The transfer of antibiotic resistance between strains of enterobacteria in chicken, calves and pigs. J. Med. Microbiol., 3, 165.

Walton, J. R. 1966. In vivo transfer of infectious drug resistance. Nature, Lond., 211, 312.

Walton, J. R. 1971. The public health implications of drug-resistant bacteria in farm animals. Ann. N.Y. Acad. Sci., 182, 358.

WatanaBe, T. 1963. Infective heredity of multiple drug resistance in bacteria. Bact. Rev., $27,87$.

Watanabe, T., AND Fukasawa, T. 1961. Episome-mediated transfer of drug resistance in Enterobacteriaceae. I. Transfer of resistance factors by conjugation. J. Bact., 81, 669 .

WiedemanN, B. 1972. Resistance transfer in vivo and its inhibition. In Bacterial plasmids and antibiotic resistance. First International Symposium on Infectious Antibiotic Resistance. Smolenice, Czechoslovakia, 1971. Edited by V. Krčméry, L. Rosival, and T. Watanabe. Springer-Verlag, Berlin, 75-91.

WiedemanN, B., KNOTHE, H., AND Doll, E. 1970. Übertragung von R-Faktoren in der Darmflora des Menschen. Zentbl. Bakt. ParasitKde, I Abt. Orig., 213, 183.

WIEDEMANN, B., KNOTHE, H., AND HölzeR, P. 1969. Untersuchungen über die Verbreitung von R-Faktoren. Zentbl. Bakt. ParasitKde, I. Abt. Orig., 212, 97. 